NASA Technical Memorandum 109153

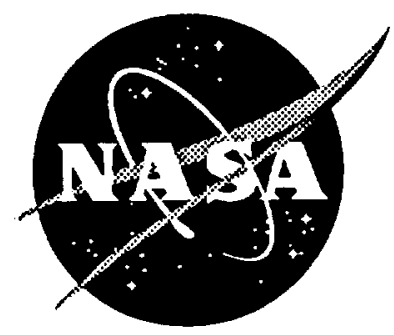

\title{
Orientation Effects on the Measurement and Analysis of Critical CTOA in an Aluminum Alloy Sheet
}

M. A. Sutton

University of South Carolina, Columbia, South Carolina

D. S. Dawicke

Analytical Services and Materials, Inc., Hampton, Virginia

J. C. Newman, Jr.

Langley Research Center, Hampton, Virginia

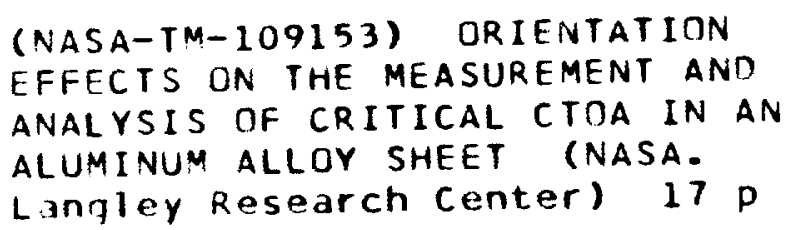

N95-13690

Unclas

September 1994

$63 / 26 \quad 0028227$

National Aeronautics and

Space Administration

Langley Research Center

Hampton, Virginia 23681-0001 


\title{
ORIENTATION EFFECTS ON THE MEASUREMENT AND ANALYSIS OF CRITICAL CTOA IN AN ALUMINUM ALLOY SHEET
}

\author{
M. A. Sutton ${ }^{1}$, D. S. Dawicke ${ }^{2}$, and J. C. Newman, Jr. ${ }^{3}$
}

\begin{abstract}
Fracture tests were conducted on $76.2 \mathrm{~mm}$ wide, $2.3 \mathrm{~mm}$ thick middle crack tension (M(T)) specimens machined from 2024-T3 aluminum sheet. The specimens were tested in the T-L orientation and comparisons were made to similar tests conducted in the L-T orientation. Measurement of critical crack tip opening angle (CTOA), applied stress, and crack front shape were made as a function of crack extension. A two-dimensional, elastic-plastic finite element analysis was used to simulate the fracture behavior for both orientations. The results indicate that the T-L orientation had a $10 \%$ lower stress at fracture than similar tests conducted in the L-T orientation. Correspondingly, the critical CTOA in the T-L tests reached a constant value of $4.7^{\circ}$ after $2-3 \mathrm{~mm}$ of crack extension and the L-T tests reached a value of $6^{\circ}$. The fracture surface of the T-L specimens were observed to remain flat, while those of the L-T specimens transitioned to a $45^{\circ}$ slant fracture after about $2-3 \mathrm{~mm}$ of crack extension. The tunneling behavior of the two orientations also differed; the T-L specimens reached a deeply tunneled stabilized crack front shape, while the L-T specimens were observed to have only a small amount of tunneling once the crack began to grow on the $45^{\circ}$ slant. The two-dimensional, elasticplastic finite element analysis was able to simulate the fracture behavior for both the T-L and L-T orientations.
\end{abstract}

\section{NOMENCLATURE}

\author{
$\triangle \mathrm{S} \quad$ Applied stress range, $\mathrm{MPa}$ \\ R Stress ratio \\ w Specimen width, mm \\ a Half crack length, $\mathrm{mm}$ \\ d Distance behind crack tip for CTOA measurement, mm \\ $\psi_{c} \quad$ Critical crack tip opening angle, degree \\ $\delta_{\mathrm{c}} \quad$ Critical crack opening displacement, $\mathrm{mm}$ \\ $\Delta \mathrm{a} \quad$ Crack extension, $\mathrm{mm}$ \\ $\Delta \mathrm{a}_{\mathrm{s}} \quad$ Surface crack extension, $\mathrm{mm}$ \\ $\Delta \mathrm{a}_{\mathrm{i}} \quad$ Mid-plane crack extension, $\mathrm{mm}$ \\ B Sheet thickness, $\mathrm{mm}$
}

\footnotetext{
${ }_{1}$ Professor, Department of Mechanical Engineering, University of South Carolina, Columbia, SC 29208

2 Senior Scientist, Analytical Services and Materials, Inc., Hampton, VA 23666

3 Senior Scientist, NASA Langley Research Center, Hampton, VA 23665
} 


\section{INTRODUCTION}

The aging of the commercial transport aircraft fleet has brought greater awareness of the deleterious effects of fatigue damage developing in pressurized fuselage structures. Analysis tools are needed to assess the influence of fatigue cracks on structural integrity and define inspection intervals. One of the objectives of the NASA Aircraft Structural Integrity Program [1] is to develop the methodology necessary to predict residual strength of cracked pressurized aircraft fuselage structures. The approach taken is to develop a local fracture criterion that can be used with shell-code finite element analyses. The fracture criterion should be able to predict large amounts of stable crack growth under conditions of large-scale yielding in thin sheet materials.

One local fracture criterion is the crack tip opening angle (CTOA) [2-6]. This criterion postulates that a crack will undergo stable crack growth when the angle made by the upper and lower crack surfaces (at a fixed distance behind the crack tip) and the crack tip, reaches a critical value. The critical CTOA criterion has been experimentally verified and successfully used to predict residual strength in laboratory specimens of 2024-T3 in the L-T orientation (i.e., the load was applied in the longitudinal or rolling direction and the crack was in the transverse direction or perpendicular to the longitudinal direction) [79]. However, this material has been shown to have anisotropic fracture properties, with the T-L orientation (i.e., the load was applied in the transverse and the crack was in the longitudinal direction) having about a $10 \%$ lower fracture toughness than the L-T orientation [10]. Moreover, in a pressurized aircraft fuselage structure, the maximum hoop stress would result in a preference for cracks developing lengthwise along the fuselage ( $T$ - $L$ orientation). As these cracks grow towards circumferential tear straps, they will either "flap", (a process where the cracked fuselage would peel open in a small local region and lead to safe decompression) or run through the tear strap. If flapping does occur, the crack will then be growing in the L-T orientation. Thus, in order to predict the residual strength of cracks in 2024-T3 aluminum alloy fuselage structures, both the L-T and $\mathrm{T}-\mathrm{L}$ properties must be known.

The objective of this study was to examine stable tearing behavior in the T-L orientation of 2024-T3 aluminum alloy. Fracture tests were conducted with measurements made of load, crack extension, and critical CTOA. The critical CTOA criterion and an elastic-plastic finite element analysis were used to predict stable crack 
growth observed in the tests. Also, the macroscopic fracture surface behavior was examined through comparisons of the stable tearing crack tunneling behavior.

\section{EXPERIMENTAL PROCEDURE}

Fracture tests were conducted on $2.3 \mathrm{~mm}$ thick 2024-T3 aluminum alloy. The yield stress and ultimate strength of the material in the L-T orientation were 345 and 490 $\mathrm{MPa}$, respectively. The yield stress and ultimate strength of the material in the T-L orientation were 303 and $475 \mathrm{MPa}$, respectively. The multi-linear representations of the uniaxial stress-strain curve for both orientations are given in Table 1. The tests were conducted on $76.2 \mathrm{~mm}$ wide middle crack tension, $\mathrm{M}(\mathrm{T})$, specimens. Measurements were made of the critical CTOA and crack-tip strain fields.

\section{Fracture Tests}

The $\mathrm{M}(\mathrm{T})$ crack configuration is shown in Fig. 1. All of the specimens were cracked in the T-L orientation (i.e., the load was applied in the transverse or perpendicular to the rolling direction and the crack was in the longitudinal direction or rolling direction). The specimens were fatigue cycled under constant amplitude loading $(\Delta S=34.5 \mathrm{MPa}$ and $\mathrm{R}=0.02)$ until the total crack length was $25.4 \mathrm{~mm}(\mathrm{a} / \mathrm{w}=0.33)$. The stable tearing tests were conducted using displacement control, with a constant loading rate of $0.002 \mathrm{~mm} / \mathrm{sec}$. During each test, measurements of load, crack length, and surface CTOA were made.

In some of the tests, the cracks were stably grown to pre-selected crack lengths. The specimens were then fatigue cycled until failure to mark the stable crack growth region. The maximum applied fatigue stress was $50-80 \%$ of the observed maximum applied stress during stable tearing and the stress ratio was $\mathrm{R}=0.8$.

\section{Measurement Techniques}

The critical CTOA during stable tearing was measured by direct observation of the surface using both the digital image correlation (DIC) and the optical microscopy (OM) technique. The OM technique uses a video camera and a long focal length microscope to image the tearing crack. The CTOA is calculated directly from points 
located on the upper and lower crack surfaces and the crack tip. Similarly, the DIC technique [11-15] measures the CTOA based on displacements of referenced surface regions located near the upper and lower crack surfaces and the crack tip. This technique uses a computer controlled video camera and lens system to digitize images of the specimen surface. To make measurements, the specimen surface was coated with a high contrast random pattern. A small region, or subset, is identified in a reference image and the relative displacement of that same subset in a subsequent image is calculated. Additional details of the DIC and OM CTOA techniques are given in References 7 and 8.

\section{FINITE ELEMENT ANALYSIS}

The elastic-plastic finite element code ZIP2D [16] was used to simulate the stable tearing behavior in the fracture tests. The program uses 3-noded, constant strain triangular elements and a critical CTOA criterion to extend the crack The elastic-plastic analysis employs the initial-stress concept [17] based on incremental flow theory and small strain assumptions. A multi-linear representation of the uniaxial stress-strain curve for 2024-T3, with the data given in Table 1, was used in the analysis with a von Mises yield criterion.

\section{Einite Element Code and Meshes}

The element size along the line of crack extension was $0.48 \mathrm{~mm}$. One half of the specimen was modeled, with the axes of symmetry along the crack line. The finite element model consisted of 821 nodes and 1447 constant strain triangular elements, as shown in Fig. 2. Normally, the nodes along the crack line and ahead of the crack tip are fixed, while those behind are free. This analysis uses fictitious springs along the crack line to change boundary conditions associated with crack extension. The stiffness of the springs are set equal to zero for the nodes behind the crack tip and assigned extremely large values for the nodes ahead of the crack tip. Monotonic loading (under displacement control) was applied to the model. Crack growth by stable tearing was governed by the critical CTOA criterion. References 8 and 9 contain the details of the elastic-plastic finite element analysis used in this work. 


\section{Critical CTOA Criterion}

The critical CTOA, $\psi_{\mathrm{c}}$, criterion is equivalent to a critical crack tip opening displacement (CTOD), $\delta_{\mathrm{c}}$, value at a specified distance, $d$, behind the crack tip equal to one element length and is given by:

$$
\psi_{c}=2 \tan ^{-1}\left(\frac{\delta_{c}}{2} / \mathrm{d}\right)
$$

The crack-tip node was released and the crack advanced to the next node whenever the CTOA equaled or exceeded a preset critical value $\left(\psi_{\mathrm{c}}\right)$ during incremental loading. This process was repeated until the crack reached the desired length. The critical CTOA value $\left(\psi_{\mathrm{c}}\right)$ was determined experimentally from surface measurements made using both the $\mathrm{OM}$ and DIC techniques.

\section{RESULTS AND DISCUSSION}

Fracture tests were conducted on 2024-T3 aluminum alloy $M(T)$ specimens in the $\mathrm{T}-\mathrm{L}$ orientation, with comparisons made to similar tests conducted on specimens in the $\mathrm{L}$ $\mathrm{T}$ orientation [7]. Surface crack growth measurements were made using an optical microscope. Surface CTOA measurements for tearing cracks were made using the OM and DIC methods. The extent of crack tunneling during stable tearing was determined through metallographic analysis of fracture surfaces subjected to a loading history that marked the crack front. The load against crack extension behavior was simulated using an elastic-plastic, two-dimensional finite element analysis.

\section{Critical CTOA Measurements}

The critical CTOA measurements for the M(T) tests are shown in Fig. 3. Also included in this figure is a scatterband that represents the measurements made on similar tests conducted in the L-T orientation. The initial CTOA values, in both the L-T and T-L tests, were high and decreased rapidly during the first $2.5 \mathrm{~mm}$ of stable crack extension. After this initial transient period, both tests reach a constant CTOA value. However, the constant CTOA value in the T-L tests was about $4.7^{\circ}$ compared to $6^{\circ}$ in the L-T tests. Both orientations had about the same $\left( \pm 1^{\circ}\right)$ scatter in the measurements. 


\section{Crack Tunneling Measurements}

A fractographic analysis of fracture surfaces was performed to quantify the crack tunneling behavior present during stable crack growth. As described in Reference 7, a distinct change in the macroscopic appearance of the fracture surface occurs when the loading changes from fatigue cycling to stable tearing. To facilitate the marking of the tunneled crack front, some specimens were fatigue precracked, loaded for a limited amount of stable crack growth, then fatigue cycled at a high stress level (high R) until failure. The stable tearing regions and the fatigue precrack regions have sharply different appearances, with a distinct interface between them. This interface denotes the shape of the crack front just prior to stable tearing. Also, a second distinct interface occurs when the loading is changed from stable tearing to high- $\mathrm{R}$ fatigue cycling, marking the shape of the crack front after the stable tearing. The interfaces between the different regions were digitized for several fracture tests.

Sequences of crack front profiles from specimens tested in both the T-L and L-T orientation, with increasing amounts of stable crack extension, are shown in Figs. $4 \mathrm{a}$ and 4b, respectively. The crack fronts shown in Fig. 4 represent trends in through-thickness crack extension rather than the progression of a single crack front, since each came from a different fracture test.

In the $\mathrm{T}-\mathrm{L}$ tests, the cracks grew, on the average, about $0.1 \mathrm{~mm}$ more in the interior than on the surface during fatigue cycling, as indicated by the first profile in Fig. 4a. The second crack front showed that stable tearing progressed faster and probably began in the specimen interior. This crack front revealed about $0.25 \mathrm{~mm}$ of surface crack extension, but the interior grew about $1 \mathrm{~mm}$. The next two crack fronts indicate that the extent of tunneling (defined as the difference between the interior crack length and the surface crack length) increased with surface crack extension. The extent of tunneling stabilized at about $2 \mathrm{~mm}$, after about $2 \mathrm{~mm}$ of surface crack extension. The fracture surface remained macroscopically flat during the entire fracture process.

In the L-T tests [7], the stable crack growth began in the interior, similar to the T$\mathrm{L}$ test, as seen by the second and third crack front profiles shown in Fig. $4 \mathrm{~b}$. However, after about $1 \mathrm{~mm}$ of surface crack extension the crack front began to straighten, with the surface catching up to the interior. This reduction in the extent of tunneling corresponded to the onset of $45^{\circ}$ slant crack growth [7]. 
The extent of tunneling that developed during stable tearing is shown in Fig. 5, where the normalized extent of tunneling (the difference between the interior crack length and the surface crack length $\left(a_{i}-a_{s}\right)$ divided by the thickness $\left.(B)\right)$ is plotted as a function of the surface crack extension $\left(\Delta a_{s}\right)$. The tunneling in the L-T tests peaked at about $70 \%$ of the thickness after about $0.8 \mathrm{~mm}$ of surface crack growth and dropped off to about $20 \%$ of the thickness for longer crack extensions. Initially the tunneling behavior in the T-L tests was identical to that in the L-T tests, but after about $1 \mathrm{~mm}$ of surface crack extension the tunneling in the T-L tests continued to increase, peaking at about $110 \%$ of the thickness.

Metallographic evaluation of both the T-L and L-T fracture surfaces did not show any significant differences; both demonstrated classical dimpled rupture profiles through the thickness and along the crack front. However, metallographic evaluations of the astested rolled sheet confirms that the grain structure is elongated in the rolling direction, though it is not totally clear how this variation contributes to observed crack growth differences.

\section{Stable Crack Growth Measurements and Simulations}

The load against surface crack extension measurements and the finite element simulations are shown in Fig. 6 for specimens tested in the T-L and L-T orientation. The peak stresses in the L-T tests were about $10 \%$ greater than that observed in the T-L tests. The finite element analyses used the stress-strain curves given in Table 1 and the critical CTOA values measured in the fracture tests to simulate the stable tearing behavior. The critical CTOA values were $6^{\circ}$ and $4.7^{\circ}$ for the L-T and T-L simulations, respectively. As seen in Fig. 6, the finite element simulations of peak stress were about $2 \%$ less than the peak stresses observed in the tests. The finite element analyses overestimated the amount of initial crack extension, but after reaching peak stress the analyses agreed well with the experimental measurements.

\section{CONCLUDING REMARKS}

Fracture tests were conducted on $\mathrm{M}(\mathrm{T})$ specimens machined from 2024-T3 sheet aluminum in the $\mathrm{T}-\mathrm{L}$ orientation and comparisons were made with similar tests conducted on specimens in the L-T orientation. Using two independent experimental methods, CTOA was determined for $10 \mathrm{~mm}$ of crack growth. Results indicated that: 
1. The CTOA trends were similar for both orientations; initially large CTOA values were measured, followed by a rapid decrease to a constant CTOA value for $\Delta \mathrm{a}>2.5 \mathrm{~mm}$.

a. For the T-L orientation, the constant CTOA was about $4.7^{\circ}$.

b. For the L-T orientation, the constant CTOA was about $6^{\circ}$.

2. A substantial difference was observed between the T-L and L-T crack growth processes.

a. The T-L fracture surface remained flat and exhibited significant tunneling (a difference in crack length between the surface crack and interior of about $2 \mathrm{~mm}$ ).

b. The L-T fracture was on a $45^{\circ}$ slant after about $2-3 \mathrm{~mm}$ of surface crack extension and initially exhibited significant tunneling, but as the stable tearing transitioned from flat-to-slant, the tunneling decreased.

3. The tests conducted in the $\mathrm{T}-\mathrm{L}$ orientation had a peak fracture stress that was $10 \%$ less than that observed in the $\mathrm{L}-\mathrm{T}$ tests.

4. The two-dimensional, elastic-plastic finite element analysis was able to simulate the peak fracture stress for both the T-L and L-T orientations.

5. The two-dimensional, elastic-plastic finite element analysis overpredicted crack growth during the first $2 \mathrm{~mm}$ of crack extension, where the surface CTOA and the amount of crack tunneling are changing.

\section{REFERENCES}

[1] Harris, C. E., "NASA Aircraft Structural Integrity Program", NASA TM 102637, April 1990.

[2] Anderson, H., "Finite Element Representation of Stable Crack Growth," Џournal of Mechanics and Physics of Solids, Vol. 21, 1973, pp. 337-356.

[3] de Koning, A. U., "A Contribution to the Analysis of Quasi Static Crack Growth in Steel Materials," in Fracture 1977, Proceedings of the 4th International Conference on Fracture, Vol. 3, pp. 25-31.

[4] Wells, A. A., "Unstable Crack Propagation in Metals: Cleavage and Fast Fracture," in Proceedings of the Cranfield Crack Propagation Symposium, Vol. 1, 1961, pp. 210-230.

[5] Wells, A. A., "Application of Fracture Mechanics at and Beyond General Yielding," British Welding Journal, Vol. 11, 1961, pp. 563-570.

[6] Wells, A. A., "Notched Bar Tests, Fracture Mechanics and Brittle Strengths of Welded Structures," British Welding Journal, Vol. 12, 1963, pp. 2-13.

[7] Dawicke, D. S. and Sutton, M. A., "Crack-Tip-Opening Angle Measurements and Crack Tunneling Under Stable Tearing in Thin Sheet 2024-T3 Aluminum Alloy", NASA-CR-191523, September 1993, also submitted to Experimental Mechanics. 
[8] Dawicke, D. S., Sutton, M. A., Newman, J. C., Jr., and Bigelow, C. A., "Measurement and analysis of Critical CTOA for an Aluminum Alloy Sheet", NASA-TM-109024, September 1993, also submitted to Fracture Mechanics: Twenty-Fifth National Symposium, ASTM STP 1220.

[9] Newman, J. C., Jr., Dawicke, D. S., and Bigelow, C. A., "Finite-Element Analysis and Measurement of CTOA During Stable Tearing in a Thin-Sheet Aluminum Alloy," Proceedings from the International Workshop on Structural Integrity of Aging Airplanes, April 1992, pp. 167-186.

[10] Grover, H. J., Hyler, W. S., and Howell, F. M., "Axial-Load Fatigue Properties of 245-T and 755-T Aluminum Alloy as Determined in Several Locations," NACATN-2928, 1953.

[11] Sutton, M.A., Bruck, H.A., Chae, T.L., and Turner, J.L., "Experimental Investigations of Three-Dimensional Effects Near a Crack Tip Using Computer Vision," International Journal of Fracture, Vol. 53, 1991, pp. 201-228.

[12] Sutton, M.A., Bruck, H.A., and McNeill, S.R., "Determination of Deformations Using Digital Correlation with the Newton Raphson Method for Partial Differential Correction," Experimental Mechanics, Vol. 29 (3), 1989, pp. 261 267.

[13] Sutton, M.A., Turner, J.L., Chae, T.L., and Bruck, H.A., "Development of a Computer Vision Methodology for the Analysis of Surface Deformation in Magnified Image," ASTM STP 1094, MICON 90. 1990, pp. 109-132.

[14] Sutton, M.A., Turner, J.L., Bruck, H.A., and Chae, T.L., "Full-Field Representation of the Discretely Sampled Surface Deformation for Displacement and Strain Analysis," Experimental Mechanics, Vol. 31 (2), 1991, pp. 168-177.

[15] Sutton, M.A. and McNeill, S.R., "The Effects of Subpixel Image Restoration on Digital Correlation Error Estimates," Optical Engineering, Vol. 27 (3), 1988, pp. 163-175.

[16] Newman, J. C., Jr., "Finite-Element Analysis of Fatigue Crack Propagation-Including the Effects of Crack Closure," Ph.D. Thesis, VPI \& State University, Blacksburg, VA, May 1974.

[17] Zienkiewicz, O. C., Valliappan, S., and King, I. P., "Elasto-Plastic Solutions of Engineering Problems, Initial Stress, Finite Element Approach," International Journal of Numerical Methods in Engineering, Vol. 1, 1969, pp. 75-100. 
TABLE 1

Multi-linear representation of the uniaxial stress-strain curve for 2024-T3

\begin{tabular}{|c|c|c|c|c|}
\hline \multicolumn{2}{|c|}{ L-T Orientation } & \multicolumn{2}{|c|}{ T-L Orientation } & \multirow{8}{*}{$\mathrm{E}=71,400 \mathrm{MPa}$} \\
\hline $\begin{array}{l}\sigma \\
(\mathrm{MPa})\end{array}$ & $\varepsilon$ & $\begin{array}{l}\sigma \\
(\mathrm{MPa})\end{array}$ & $\varepsilon$ & \\
\hline 345 & 0.00483 & 303 & 0.00425 & \\
\hline 390 & 0.015 & 355 & 0.015 & \\
\hline 430 & 0.04 & 403 & 0.04 & \\
\hline 470 & 0.1 & \begin{tabular}{|l|l}
448 \\
\end{tabular} & 0.1 & \\
\hline 490 & 0.16 & 476 & 0.16 & \\
\hline 490 & 0.2 & 476 & 0.2 & \\
\hline
\end{tabular}

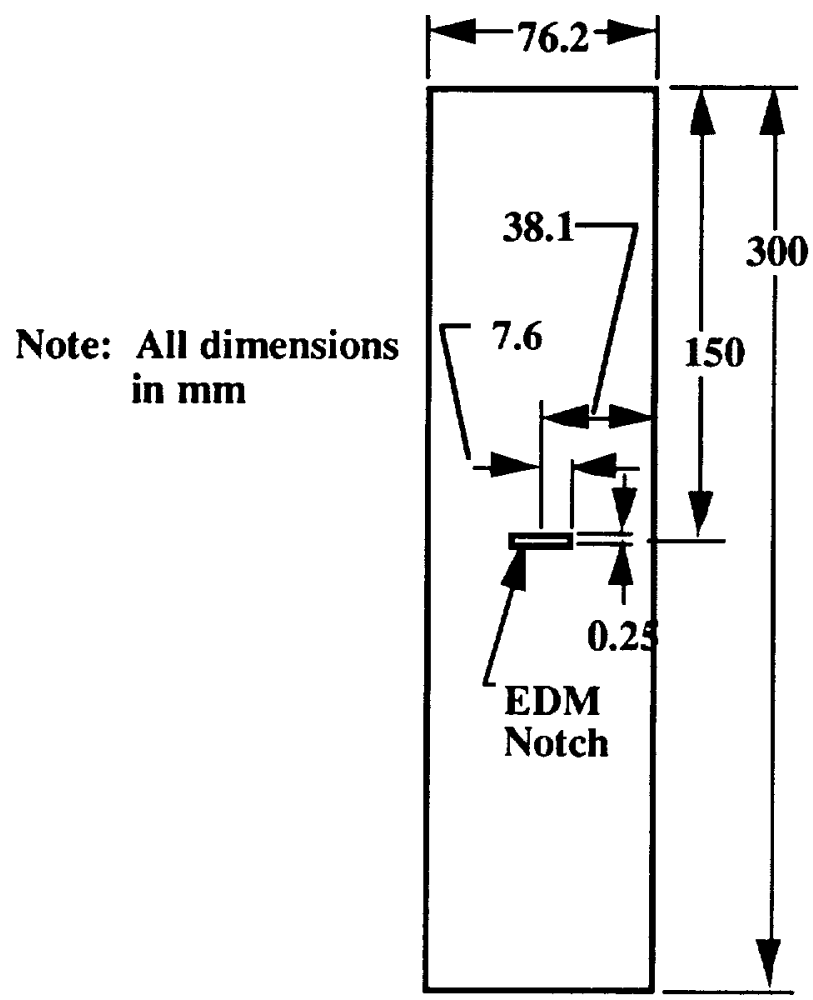

Figure $1 \quad M(T)$ specimen configuration. 


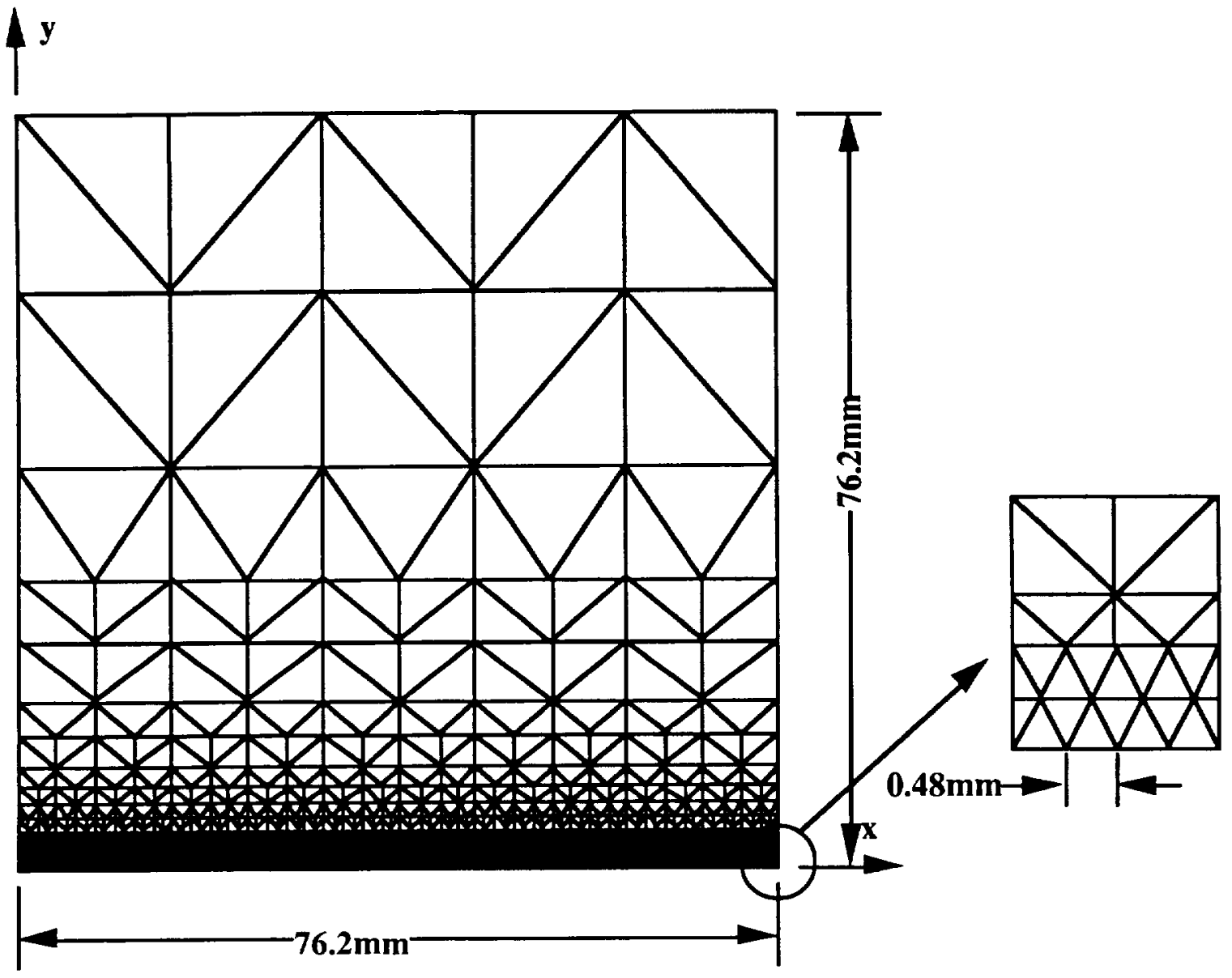

Figure 2 Finite element model of $1 / 2$ of the $M(T)$ specimen. 


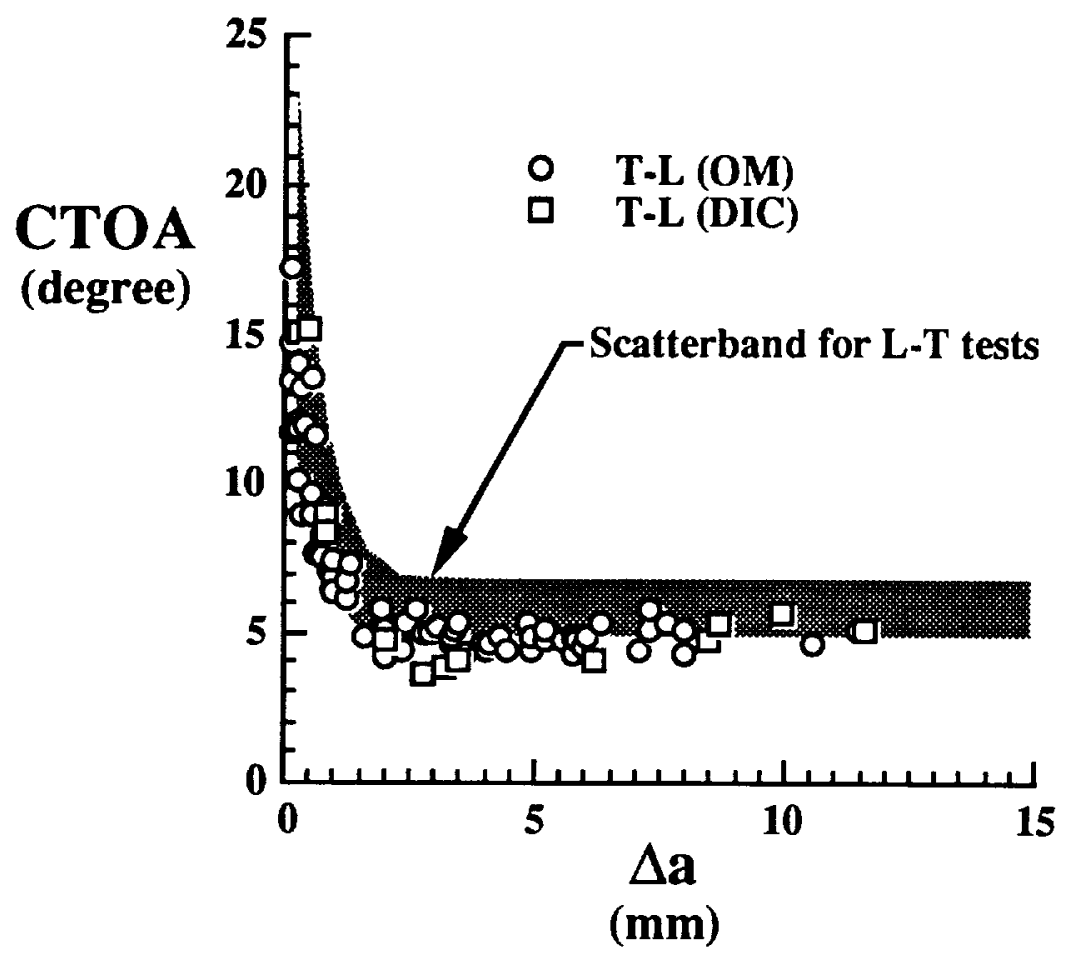

Figure 3 Critical CTOA measurements for the $M(T)$ specimens in the $T-L$ orientation (precracked at a stress range of $\Delta S=34.5 \mathrm{MPa}$ ) and the scatterband for similar M(T) L-T tests [7]. 


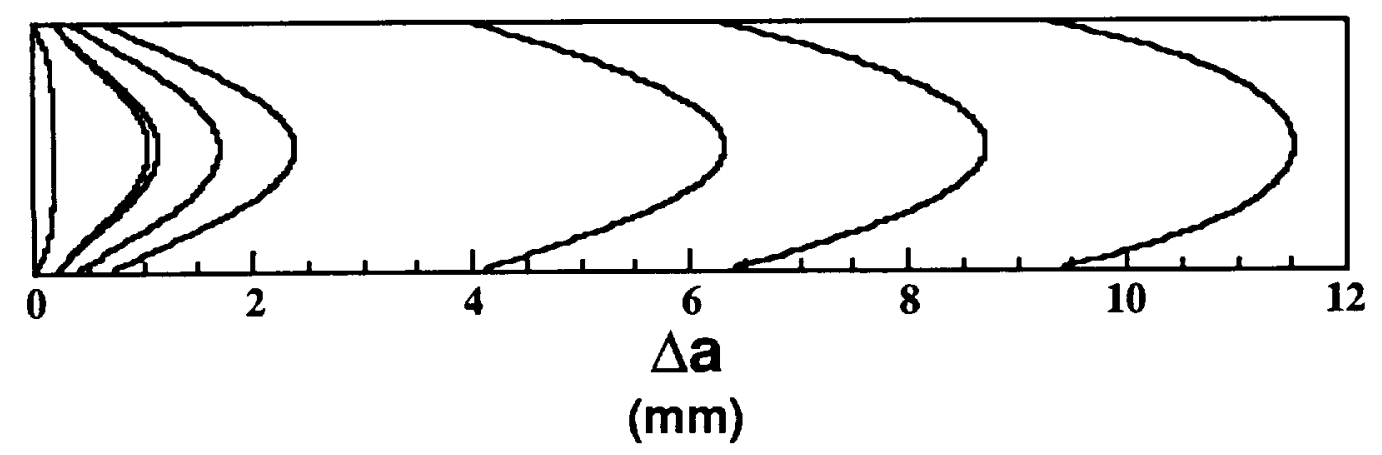

a. T-L orientation

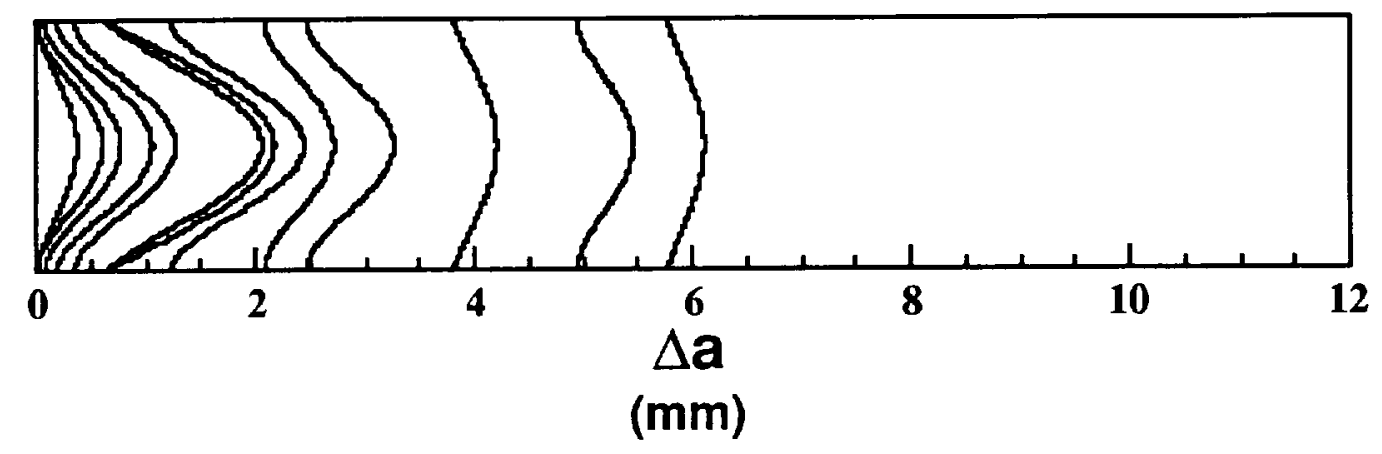

b. L-T orientation [7]

Figure 4 Crack front profiles after stable tearing for specimens tested in the T-L and L-T orientations. 


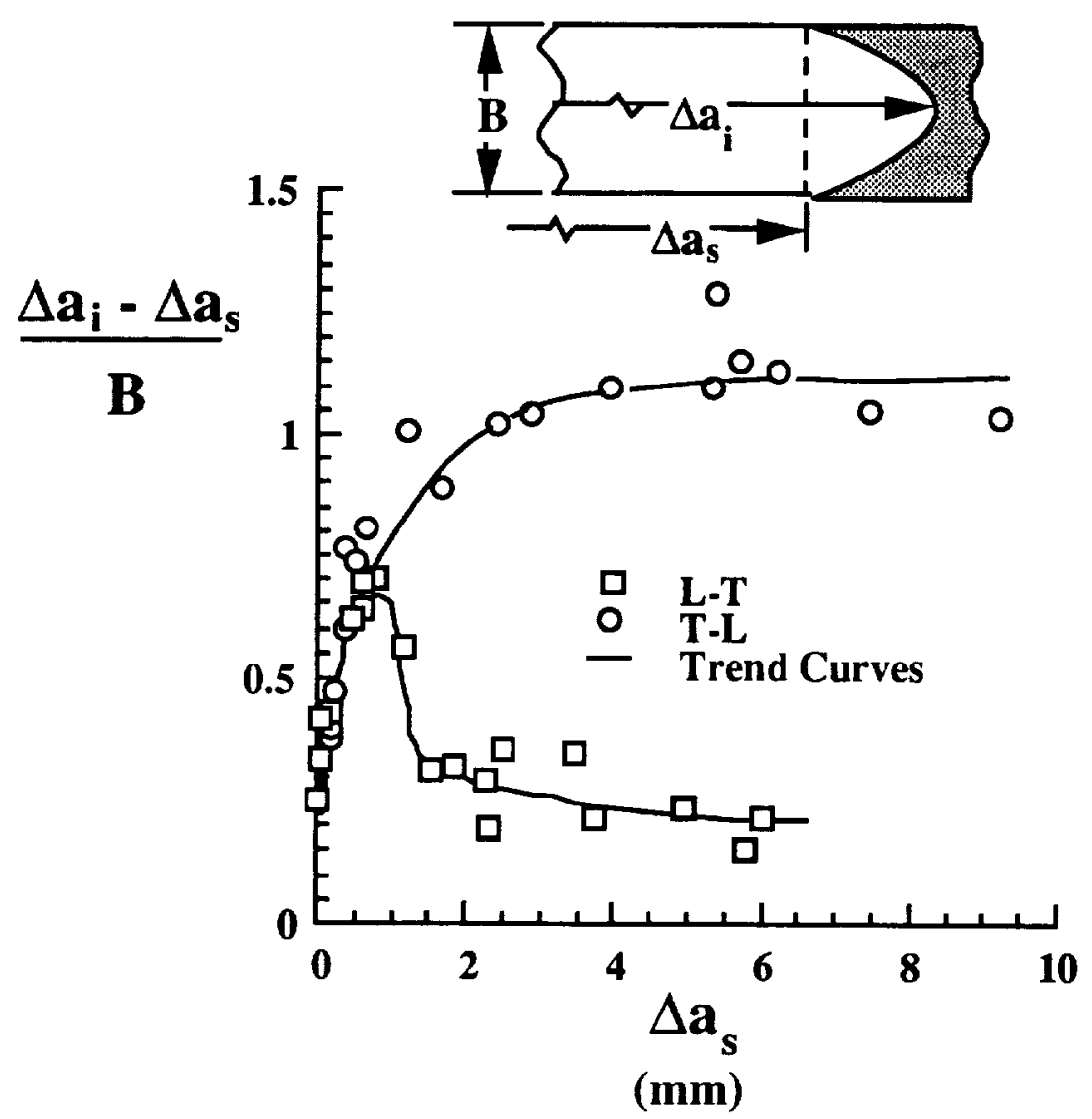

Figure 5 Extent of crack tunneling for specimens tested in the T-L and L-T orientations. 


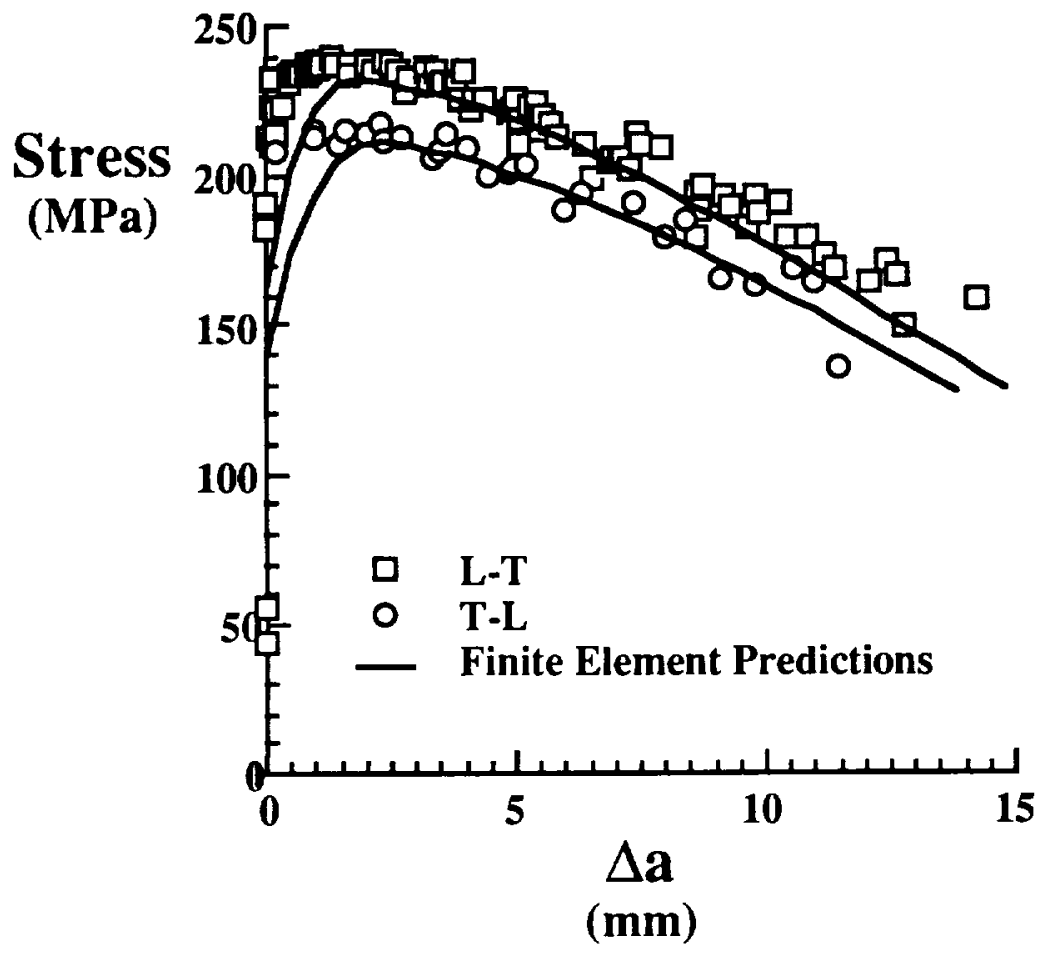

Figure 6 Stress against surface crack extension measurements and finite element predictions for tests conducted on specimens in the $\mathrm{L}-\mathrm{T}$ and $\mathrm{T}-\mathrm{L}$ orientation. 


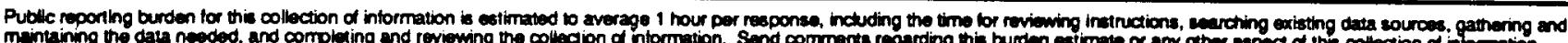

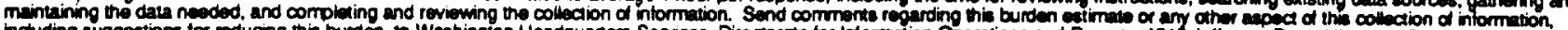

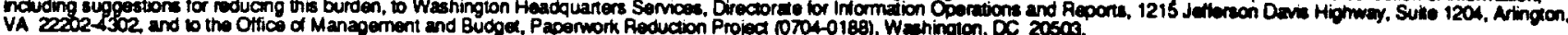

\begin{tabular}{|l|l|l|}
\hline 1. AGENCY USE ONLY (Leave blank) & $\begin{array}{l}\text { 2. REPORT OATE } \\
\text { September } 1994\end{array}$ & $\begin{array}{l}\text { 3. REPOAT TYPE AND DATES COVERED } \\
\text { Technical Memorandum }\end{array}$ \\
\hline
\end{tabular}

Orientation Effects on the Measurement and Analysis of Critical CTOA in an Aluminum Alloy Sheet 5. FUNDING NUMBERS

WU 538-02-10-01

6. AUTHOR(S)

M. A. Sutton, D. S. Dawicke, and J. C. Newman, Jr.

7. PERFORMING ORGANIZATION NAME(S) AND ADDRESS(ES)

NASA Langley Research Center

8. PERFORMING ORGANIZATION

Hampton, VA 23681-0001

REPORT NUMBEA

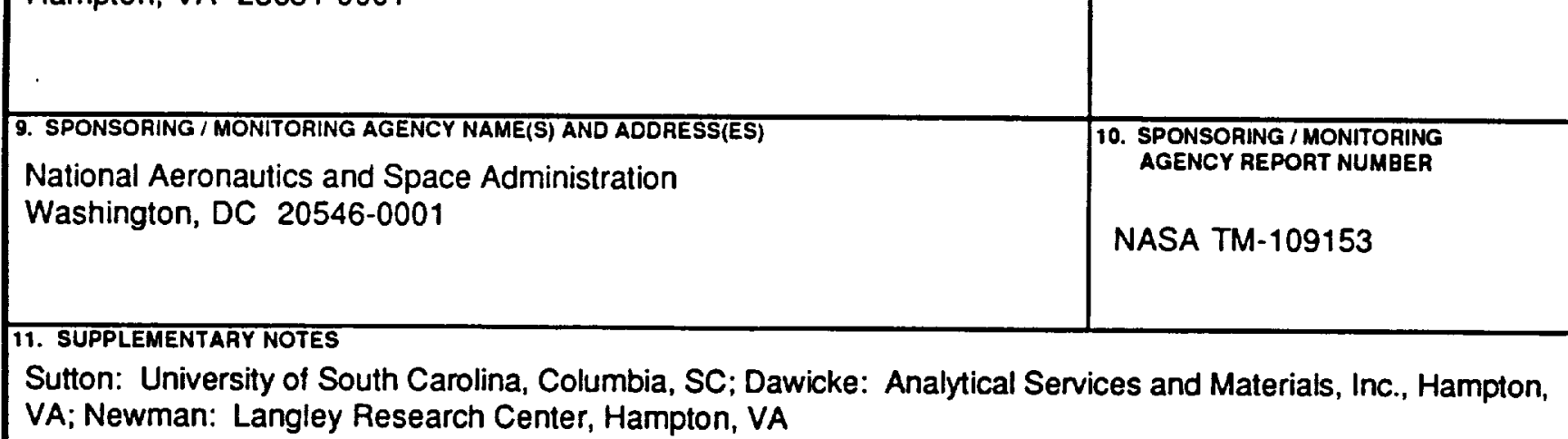

\begin{tabular}{|l|l|}
\hline 12a. DISTRIBUTION / AVAILABILITY STATEMENT & 12b. DISTRIBUTION CODE \\
Unclassified - Unlimited & \\
Subject Category - 26 & \\
\hline 13. ABSTRACT (Maximum 200 worda) & \\
\hline
\end{tabular}

Fracture tests were conducted on $76.2 \mathrm{~mm}$ wide, $2.3 \mathrm{~mm}$ thick middle crack tension $(M(T))$ specimens machined from 2024-T3 aluminum sheet. The specimens were tested on the $T-L$ orientation and comparisons were made to similar tests conducted in the L-T orientation. Measurement of critical crack tip opening angle (CTOA), applied stress, and crack front shape were made as a function of crack extension. A two-dimensional, elastic-plastic finite element analysis was used to simulate the fracture behavior for both orientations. The results indicate that the T-L orientation had a $10 \%$ lower stress at fracture than similar tests conducted in the L-T orientation.

Correspondingly, the critical CTOA in the $T-L$ tests reached a constant value of $4.7^{\circ}$ after $2-3 \mathrm{~mm}$ of crack extension and the $L-T$ tests reached a value of $6^{\circ}$. The fracture surface of the $T-L$ specimens were observed to remain flat, while those of the L-T specimens transitioned to a $45^{\circ}$ slant fracture after about $2-3 \mathrm{~mm}$ of crack extension. The tunneling behavior of the two orientations also differed; the $T-L$ specimens reached a deeply tunneled stabilized crack front shape, while the L-T specimens were observed to have only a small amount of tunneling once the crack began to grow on the $45^{\circ}$ slant. The two-dimensional, elastic-plastic finite element analysis was able to simulate the fracture behavior for both the $T-L$ and $L-T$ orientations.

14. SUBJECT TERMS

Fracture; CTOA; Aluminum; Thin-sheet material; Orientation; Stable tearing

15. NUMBER OF PAGES 16

\begin{tabular}{|l|l|l|}
\hline $\begin{array}{l}\text { 17. SECURITY CLASSIFICATION } \\
\text { OF REPORT } \\
\text { Unclassified }\end{array}$ & $\begin{array}{l}\text { 18. SECURITY CLASSIFICATION } \\
\text { OF THIS PAGE } \\
\text { Unclassified }\end{array}$ & $\begin{array}{l}\text { 19. SECURITY CLASSIFICATION } \\
\text { OF ABSTRACT }\end{array}$ \\
\hline
\end{tabular}

